\title{
Retrospective Surveillance of Intussusception in South Africa, 1998-2003
}

\author{
S. W. Moore, ${ }^{1}$ M. Kirsten, ${ }^{2}$ E. W. Müller, ${ }^{2}$ A. Numanoglu, ${ }^{3}$ M. Chitnis, ${ }^{4}$ E. Le Grange, ${ }^{5}$ B. Banieghbal, ${ }^{6}$ \\ and G. P. Hadley
}

'Division of Paediatric Surgery, University of Stellenbosch, Tygerberg, and Departments of Paediatric Surgery, ${ }^{2}$ Steve Biko Academic Hospital and Kalafong Hospital, Pretoria, ${ }^{3}$ Red Cross Hospital, University of Cape Town, Cape Town, ${ }^{4}$ Frere Hospital, East London, ${ }^{5}$ University of the Free State, Bloemfontein, ${ }^{6}$ University of Witwatersrand, Johannesburg, and ${ }^{7}$ University of Kwa-Zulu/Natal, Durban, South Africa

Background. Intussusception is a common gastrointestinal emergency in children and appears to have a somewhat different clinical spectrum in developing countries. Its etiology is still unclear, but a link to infective agents and viruses has been highlighted. This study aimed to assess the clinical spectrum and prevalence of intussusception in children from the diverse South African population.

Methods. Retrospective data were obtained from 9 participating pediatric referral units on the occurrence of intussusception in South African children (<14 years old) during a 6-year period (1998-2003). Results were correlated with national population statistics. Intussusception was anatomically classified into ileoileal, ileocolic, and colocolic types. The clinical features, management, outcome, and possible causes were examined.

Results. We reviewed the occurrence and clinical spectrum of intussusception in 423 children (age, 0-14 years) presenting with acute intussusception to 9 pediatric surgical centers. The mean duration of symptoms was 1.5 days, but a delayed presentation was common (median delay, 2.3 days). Intussusception occurred throughout the year, with a peak in the summer months. The majority of patients $(89 \%)$ were $<2$ years old, and $78 \%$ presented at age 3-18 months of age. Crude population estimates indicate an occurrence of 1 case per 3123 population $<2$ years old. Only $11 \%$ of patients presented after 2 years of age, and the age at presentation was significantly lower $(P<.05)$ in black African patients. All ethnic groups were affected. In $84 \%$ of patients, intussusception occurred at the ileocolic region junction, in 7\% it was ileoileal, and in $9 \%$ it was colocolic. Colocolic intussusception appeared more common in black African patients, and associated pathologic conditions (polyps and Burkitt's lymphoma) occurred mainly in older children. Surgical intervention was required in $81 \%$ of patients and involved resection of gangrenous bowel in $40 \%$.

Conclusion. Intussusception appears to be a relatively frequent occurrence in children in South Africa. Although the clinical spectrum appears to vary, there is an apparent link to intestinal infection, which requires further investigation. A collaborative approach is required to ascertain the relationship of intussusception to preventable infections and to improve its diagnosis and management.

The invagination of a part of the bowel into another distal portion (or intussusception) is one of the most

Potential conflicts of interest: none reported.

Financial support: none reported.

Supplement sponsorship: This article is part of a supplement entitled "Rotavirus Infection In Africa: Epidemiology, Burden of Disease, and Strain Diversity," which was prepared as a project of the Rotavirus Vaccine Program, a partnership among PATH, the World Health Organization, and the US Centers for Disease Control and Prevention, and was funded in full or in part by the GAVI Alliance.

Presented in part: Pan-African Paediatric Surgeons Association Conference, Blantyre, Malawi, 2002.

Reprints or correspondence: Dr Moore, Department of Paediatric Surgery, Faculty of Medicine, University of Stellenbosch, P0 Box 19063, Tygerberg 7505, South Africa (swm@gerga.sun.ac.za).

The Journal of Infectious Diseases 2010;202(S1):S156-S161 (C) 2010 by the Infectious Diseases Society of America. All rights reserved. 0022-1899/2010/20205S1-0021\$15.00

DOI: $10.1086 / 653563$ common causes of intestinal obstruction in young children, particularly those $<2$ years old. The most frequent anatomic presentation is invagination of the terminal ileum into the colon, but colocolic and ileoileal intussusception are not uncommon. Common clinical features include rectal bleeding (in $81 \%$ of patients), vomiting (in 78\%), and abdominal pain and colic (in 65\%), and an abdominal mass may be palpable in $\sim 62 \%$ of patients $[1,2]$.

The etiology of intussusception is unknown, with an anatomic cause identified in only $<10 \%$ of cases. The majority of cases occur in children $<2$ years of age, the so-called "idiopathic" group. In this cohort, intussusception often occurs after respiratory or gastrointestinal infection (diarrhea) in younger children, suggesting an 
etiological role for pathogenic agents in its pathogenesis [3]. In older children, intussusception occurs much less commonly but may result from an anatomic abnormality that forms a "lead point" or predisposing condition (eg, lymph node, lymphoma, intestinal polyp or tumor, Meckel's diverticulum) [3].

A proposed link between viral infective causes and intussusception was highlighted by reports of a spatial and temporal increased risk of intussusception 3-14 days after initial vaccination with the rhesus reassortant rotavirus (RRV) vaccine [49]. This association led to the withdrawal of this specific vaccine from the market [10]. Despite arguments that the reported risk with the RRV vaccine was significantly less than that reported $[4,11]$, this specter has lingered over the development of new rotavirus vaccine candidates and resulted in the very large safety studies that aim to eliminate an associated risk of intussusception for the 2 new vaccines $[12,13]$. The World Health Organization (WHO) examined the original trial data and, although no significant association was detected in these trials with $>60,000$ subjects, recommended that postmarketing surveillance for intussusception be required where rotavirus vaccines were introduced [14]. The most recent review of the safety data, generated by countries using the 2 vaccines licensed by the WHO Global Advisory Committee on Vaccine Safety, reported that there was no statistically significant evidence of vaccine-associated adverse events and that an intussusception risk of the order of magnitude of the RRV vaccine could be ruled out [15]. Nevertheless, WHO recommends that postmarketing surveillance be conducted in countries that introduce rotavirus vaccine.

South Africa recently made the decision to introduce rotavirus vaccine into the routine schedule for infants from the Expanded Program on Immunization, based on the high burden of disease [16]. Rotavirus has been well documented as an important cause of hospitalizations among young children in South Africa [17]. The viral infection in South Africa tends to occur in young infants $(76 \%$ are infected at before 12 months of age) and show a strong seasonal pattern of disease with an autumn-winter peak [18].

Intussusception in South Africa also occurs predominantly in this age group of young children, although it appears to occur more commonly in spring and summer than in winter, thus showing no temporal association with the rotavirus season $[19,20]$. This phenomenon has been reported elsewhere, where natural infection with wild-type human rotaviruses has not been associated with intussusception $[8,19,21]$. Previous reports of intussusception in South African infants highlight the frequent delay in presentation, as well as differences in the age at presentation and a higher incidence of colocolic intussusception in older black patients [22-25]. The aim of this study was to document the prevalence of intussusception in South Africa in 1998-2003, thus providing important background information with which to interpret rotavirus vaccine postmarketing surveillance as the vaccine is introduced in South Africa in 2009.

\section{PATIENTS AND METHODS}

Data were obtained from 9 participating pediatric referral units for intussusception representing 6 of the 9 provinces of South Africa during a 5-year period (1998-2003). Intussusception was anatomically classified into ileoileal, ileocolic, and colocolic types, and data on age, sex and ethnic group, clinical features, and possible causes were also analyzed. The anatomic pathology of the intussusception (as delineated by ultrasonography, contrast studies, or computed tomography or as defined at surgery) was recorded, as well as the anatomic pathological evaluation findings, the treatment, and the outcome.

Population data were obtained from the census statistics of the Central Statistical Services of South Africa [26]. The statistics for children $<2$ years of age were calculated province by province, correcting census data to allow for missing centers based on the respective municipal populations.

Statistical analysis. The statistical analysis was conducted using means, medians, and nonparametric tests for small numbers.

Ethical permission. This research project has been approved by the research committee at Stellenbosch University (reference no. N04/09/161) and was conducted according to the accepted ethical codes and guidelines, as outlined in the Declaration of Helsinki.

\section{RESULTS}

A total of 423 children (age, $<14$ years) were confirmed to have intussusception in 9 specialist units in South Africa (19982003). Intussusception occurred in all months of the year, with seasonal peaks in the late spring and summer months of the southern hemisphere (Figure 1). A further analysis of the monthly proportion of black African patients with intussusception failed to demonstrate a clear temporal relationship with the published incidence of rotavirus infection [18] (Figure 2).

The male-female ratio was $1.3: 1$, and the mean age at presentation was 12.14 months (range, 1-144 months). Ninetyone percent of chidlren (384) presented before their second birthday (78\% between 3 and 18 months of age). Forty-seven children (11\%) presented after 2 years of age. The mean duration of symptoms was 1.5 days, but a delayed presentation was common, with a median delay of 2.3 days. Of 423 patients with intussusception, 320 (76\%) were of black African ethnic origin, $92(22 \%)$ were of mixed ancestry or Indian ancestry, and only $10(2 \%)$ were of white ancestry, in keeping with the South African population profile [26].

The site of intussusception was ileocecal in $84 \%$ of patients, colocolic in $9 \%$, and ileoileal in $7 \%$. This anatomic pattern 


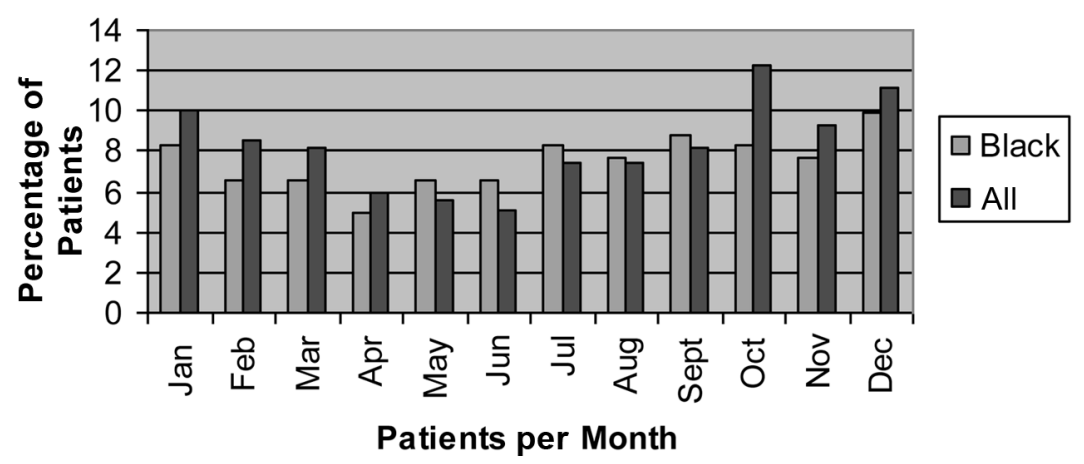

Figure 1. Seasonal variation in intussusception in South African children (1998-2003).

differed between ethnic groups, however; colocolic intussusception occurred in $9 \%$ overall but in 14\% of black African patients. Intussusception also occurred at a significantly younger age in black African children $(P<.05)$ (Table 1$)$.

The known predisposing factors, clinical features, and outcome are shown in Table 2. Surgical intervention was required in $81 \%$ of the 304 patients with known results, involving resection of gangrenous bowel in $40 \%$.The majority of patients were treated successfully, with only 9 deaths (2\%) These patients all had intestinal necrosis or perforation and advanced intra-abdominal sepsis at admission.

Although a history of a febrile illness and minor episodes of diarrhea were common, severe diarrhea was recorded in only 9 patients, with a pathogen identified in the stool sample in only 1 (Shigella species) although other possible contributors were identified in another 4 (cytomegalovirus in 1, Candida species in 2, and mucormycosis in 1). Other associated pathologies were uncommon, occurred mainly in older children, and included Puetz-Jeghers polyps ( 2 children), other small bowel polyps (1) lymphadenopathy (3), adhesions (1), and intestinal malrotation (4).

This study population comprises most of the large pediatric centers of South Africa and all specialist pediatric surgical units, which would receive referrals for intussusception. However, because only 6 of the 9 provinces were represented in this study, calculations of occurrence were based on the $<2$-year age group from those provinces $(n=1,433,762$, based on 2001 census data [26]); data were roughly corrected for missing centers based on the municipality figures for children $<2$ years old. Applying the number of patients $<2$ years of age with intussusception ( 384 patients) to the population of children $<2$ years old (final corrected population, 1,199,328 children) during the period under review would give an occurrence of 1 case of intussusception per 3123 population, or 32 cases of intussusception per 100,000 children per year.

\section{DISCUSSION}

Intussusception is one of the most common causes of intestinal obstruction in young children, particularly in those $<2$ years old. Although the etiology in this age group largely remains unknown, intussusception is believed by many to occur more commonly in developing countries, possibly owing the higher incidence of infection. Studies in Latin America and the United States indicate rates of intussusception of approximately 3040 cases per 100,000 children, with slightly higher rates in Eu-

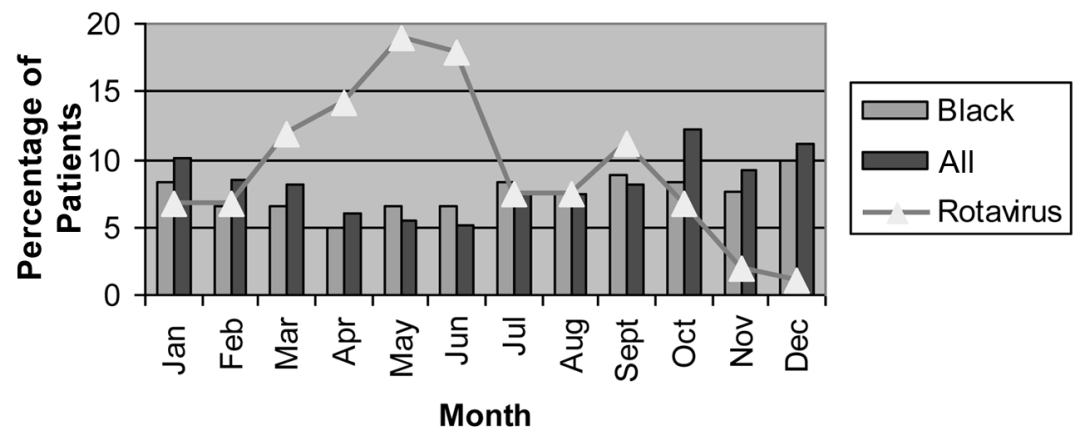

Figure 2. Graph showing seasonal variation in the incidence of intussusception in the black patient group (percentage of patients), compared with the total population of patients. Line graph demonstrates the lack of relationship with seasonal variation in rotavirus infection in black African patients in South Africa [18]. 
Table 1. Epidemiological data for 225 patients with intussusception

\begin{tabular}{|c|c|c|c|c|c|}
\hline \multirow[b]{2}{*}{ Ethnic group } & \multirow{2}{*}{$\begin{array}{c}\text { No. of } \\
\text { patients }\end{array}$} & \multirow{2}{*}{$\begin{array}{c}\text { Mean } \\
\text { age, } \\
\text { months }\end{array}$} & \multicolumn{3}{|c|}{$\begin{array}{l}\text { No. (\%) of patients, by site } \\
\text { of intussusception }\end{array}$} \\
\hline & & & Ileoileal & Ileocecal & Colocolic \\
\hline White & 12 & 15.1 & 1 (8) & $9(75)$ & $2(17)$ \\
\hline Mixed ancestry & 68 & 16.7 & $2(3)$ & $66(97)$ & 0 \\
\hline Black & 145 & $9.44^{a}$ & $16(11)$ & $109(75)$ & $20(14)$ \\
\hline
\end{tabular}

NOTE. Data were incomplete for 44 patients.

a $P<.05$.

rope [27]. In this study, a similar rate of 32 cases per 100,000 children was calculated, which is comparable to that observed in these regions and in other studies in Africa [28]. However, rates in Asia have consistently been reported to be significantly higher than in other regions [28-31]. Intussusception is particularly frequent in China, where an annual incidence rate of 418.1 cases per 100,000 child-years has been reported in Suzhou in the $<1$-year age group [28]. Similar high rates were observed in Vietnam [32]. Thus, it is important to assess the background levels of intussusception in a country that is planning to introduce the rotavirus vaccine.

The pathophysiology of intussusception is still incompletely understood, but the disease often follows an intestinal or respiratory viral infection. It is thought that an increase and swelling of the extensive lymphoid tissue in the intestinal wall then results in mechanical forces that cause invagination of the proximal into the distal bowel. More recently, significant distal ileal wall thickening and lymphadenopathy have been identified during acute rotavirus infection, suggesting a plausible mechanism by which rotavirus infection could lead to intussusception [33]. Nevertheless, most natural history reports have not observed a link with wild-type rotavirus infection $[8,19]$, despite the reported association of the RRV vaccine with this condition.

In addition to infective causes, intussusception is also associated with Henoch-Schönlein purpura and other immunological conditions, suggesting a possible immunological role in its pathogenesis in younger children. The case for an immunological link is strengthened by a distinct peak incidence between 3 and 18 months of age, which may coincide the change from breast to cow's milk feeding (often a time for heightened allergic response).

In this study, many patients presented late in the course of illness (median delay, 2.3 days), possibly because of cultural and logistical factors concerning hospital visits. The common clinical features of rectal bleeding, vomiting, abdominal pain and colic, and a palpable abdominal mass were only present in $\sim 50 \%$ of cases. This scenario is not uncommon in developing countries, can lead to considerable diagnostic difficulties, and may contribute to the late presentation and high rate of operative reduction in many cases.

The incidence of associated pathology or a lead point was seen in only $2.1 \%$ of patients, in keeping with other locally available data (ie, $4.2 \%$ observed [34]). Although ileocolic intussusception occurred in $84 \%$ of patients in this study, there was a higher incidence ( $9 \%$ ) of colocolic intussusception than reported in other surveys $[1,3,24]$. Furthermore, the $14 \%$ of

Table 2. Clinical presentation and management of $\mathbf{4 2 3}$ patients with intussusception, by age group

\begin{tabular}{|c|c|c|c|}
\hline \multirow[b]{2}{*}{ Presentation and management } & \multicolumn{3}{|c|}{ No. of patients, by age group } \\
\hline & $\begin{array}{c}<12 \text { months } \\
(n=336)\end{array}$ & $\begin{array}{l}13-24 \text { months } \\
(n=40)\end{array}$ & $\begin{array}{c}>25 \text { months } \\
(n=47)\end{array}$ \\
\hline \multicolumn{4}{|l|}{ Predisposing conditions } \\
\hline Anatomic anomaly (e.g., lead point) & 4 & 0 & 7 \\
\hline Herbal enema $^{a}$ & 3 & 0 & 0 \\
\hline \multicolumn{4}{|l|}{ Clinical presentation } \\
\hline Intestinal obstruction or rectal bleeding & 169 & 29 & 20 \\
\hline Rectal bleeding only & 41 & 4 & 5 \\
\hline Intestinal perforation & 14 & 5 & 4 \\
\hline Septic shock & 6 & 2 & 2 \\
\hline Insufficient data & 106 & 12 & 16 \\
\hline \multicolumn{4}{|l|}{ Management } \\
\hline Nonsurgical reduction & 42 & 6 & 9 \\
\hline Surgical reduction & 104 & 12 & 31 \\
\hline Resection gangrenous bowel & 83 & 10 & 7 \\
\hline Insufficient data & 107 & 12 & 0 \\
\hline Outcome of death & 3 & 4 & 2 \\
\hline
\end{tabular}


colocolic intussusception observed in black African patients in this series is also higher than rates in other reports [24]. The explanation for this phenomenon is not clear, but it may be associated with intestinal infection. In older children, there is a more distinct association with coexisting pathology, such as lymphadenopathy, Meckel's diverticulum, and polyps, but this usually contributes $<15 \%$ of the total number of cases $[35,36]$. In the current study, only $3.7 \%$ of cases were associated with one of these conditions. Malrotation may also predispose to intussusception [37] and was present in 4 cases (1.6\%) of the 225 case patients in this series (Table 1). Less common associations include lymphoma, intestinal tumors, and intestinal parasites.

In this study, there was a relatively low overall rate of hydrostatic reduction of the intussusception (19\% of cases where sufficient information was available) (Table 2). Forty percent of patients submitted to surgery underwent intestinal resection because of perforation, peritonitis, gangrenous bowel, or failure to reduce even at surgery. This reflects a much higher incidence of surgery and bowel resection than seen in some international settings [38, 39] but is more representative of what occurs in developing countries [35]. The finding may reflect the severity of disease in African patients; this may be partly due to late presentation, but a viral link may also play a part in making intussusception more resistant to nonoperative reduction [21].

The ethnic mix of patients with intussusception in this sample approximates the population in South Africa and can be regarded as being largely representative, with intussusception occurring equally in all population groups. In rates similar to those in other international reports, $89 \%$ of patients in this study presented before the age of 2 years, and $78 \%$ were between 3 and 18 months of age. The mean age at presentation was 12 months, and only $11 \%$ of patients presented after 2 years of age. In contrast to other ethnic groups in South Africa, among whom a somewhat later age of presentation was encountered, black African patients presented at a mean of 9 months, a significant difference $(P<.05)$.

Finally, although we and other investigators [40, 41] have concluded that there is no confirmed correlation between the occurrence of intussusception and rotavirus infection, the question will be resolved only by a prospective study of the potential association. The question as to a potential risk of association with rotavirus vaccination also remains open, because intussusception also occurs with other vaccines (eg, diphtheria-pertussis-tetanus vaccine [42] and oral poliovirus vaccine [43, 44]).

There are still gaps in our knowledge of intussusception with respect to its etiology and especially any mechanisms by which the rhesus RRV might cause it to occur. As the new rotavirus vaccines are introduced into the routine childhood immunization schedules, postlicensure surveillance for intussusception is indicated and may be instrumental in any further under- standing of the epidemiology of this condition and further assessment of the safety of future vaccines [15]. This study provides some national South African data on intussusception occurrence and epidemiology in a country where rotavirus vaccine introduction is imminent and where postmarketing surveillance is required.

\section{Acknowledgments}

We acknowledge the encouragement, help, and support given by Prof. Duncan Steele in the completion of this project.

\section{References}

1. Crankson SJ, Al-Rabeeah AA, Fischer JD, Al-Jadaan SA, Namshan MA. Idiopathic intussusception in infancy and childhood. Saudi Med J 2003; $24: S 18-S 20$.

2. Lai AH, Phua KB, Teo EL Jacobsen AS. Intussusception: a three-year review. Ann Acad Med Singapore 2002;31:81-85.

3. Fallat ME. Intussusception. In: Ashcraft K, Murphy JP Sharp RJ, Sigalet DL, Snyder CL, eds. Paediatric Surgery. 3rd ed. Philadelphia, PA: WB Saunders, 2000:518-526.

4. Murphy BR, Morens DM, Simonsen L, Chanock RM, La Montagne JR, Kapikian AZ. Reappraisal of the association of intussusception with the licensed live rotavirus vaccine challenges initial conclusions. J Infect Dis 2003; 187:1301-1308.

5. Murphy TV, Wharton M. More on rotavirus vaccination and intussusception. N Engl J Med 2002;346(3):211-212.

6. Murphy TV, Gargiullo PM, Massoudi MS, et al. Intussusception amoung infants given an oral rotavirus vaccine. N Engl J Med 2001; 344:564-572.

7. Peter G, Myers MG. Intussusception, rotavirus, and oral vaccines: summary of a workshop. Pediatrics 2002; 110:e67-e73.

8. Rennels MB, Parashar UD, Holman RC, Le CT, Chang HT, Glass RI. Lack of association between intussusception and wild or vaccine rotavirus infection. Pediatr Infect Dis J 1998; 17:924-925.

9. Centers for Disease Control and Prevention. Rotavirus vaccine for the prevention of rotavirus gastroenteritis among children: Recommendations of the Advisory Committee on Immunisation Practices (ACIP). MMWR Morb Mortal Wkly Rep 1999; 48:1-20.

10. Centers for Disease Control and Prevention. Withdrawal of rotavirus vaccine recommendation. MMWR 1999; 48:1007.

11. Simonsen L, Viboud C, Elixhauser A, Taylor RJ, Kapikian AZ. More on RotaShield and intussusception: the role of age at the time of vaccination. J Infect Dis 2005; 192(Suppl 1):S36-S43.

12. Vesikari T, Matson DO, Dennehy P, et al. Safety and efficacy of a pentavalent human-bovine (WC3) reassortant rotavirus vaccine. N Engl J Med 2006; 354:23-33.

13. Ruiz-Palacios GM, Perez-Schael I, Velazquez FR, et al. Safety and efficacy of an attenuated vaccine against severe rotavirus gastroenteritis. N Engl J Med 2006; 354:11-22.

14. WHO report of the Global Advisory Committee on Vaccine Safety. Weekly Epidemiol Rec 14 July 2006; 81:273.

15. WHO report of the Global Advisory Committee on Vaccine Safety. Weekly Epidemiol Rec 30 Jan 2009; 84:37-40.

16. New vaccines expected to save lives of 14 children a day in SA. Cape Times, 25 September 2008. http://www.capetimes.co.za/index.php?/ farticleld $=4610813$.

17. Steele AD, Peenze I, de Beer MC, et al. Anticipating rotavirus vaccines: epidemiology and surveillance of rotavirus infection in South Africa. Vaccine 2003; 21:354-360.

18. Steele AD, Hay IT, Alexander JJ. Rotavirus-associated gastroenteritis in Ga-Rankuwa, South Africa. J Clin Microbiol 1986; 23:992-994. 
19. Chang EJ, Zangwill KM, Lee H, Ward JI. Lack of association between rotavirus infection and intussusception: implications for use of attenuated rotavirus vaccine. Pediatr Infect Dis J 2002;21:97-102.

20. Velazquez FR, Luna G, Cedillo R, Torres J, Munoz O. Natural rotavirus infection is not associated to intussusception in Mexican children. Pediatr Infect Dis J 2004; 23:S173-S178.

21. O'Ryan M, Lucero Y, Pena A, Valenzuela MT. Two year review of intestinal intussusception in six large public hospitals of Santiago, Chile. Pediatr Infect Dis J 2003;22:717-721.

22. Isdale JM, Saunders WC. Intussusception in Johannesburg: a review of 81 cases. S Afr Med J 1986; 69:610-611.

23. Postma MH, Hadley GP. Intussusception in black children. S Afr Med J 1985; 68:405-406.

24. Grant HW, Buccimazza I, Hadley GP. A comparison of colo-colic and ileo-colic intussusception. J Pediatr Surg 1996;31:1607-1610.

25. Mayell MJ. Intussusception in infancy and childhood in Southern Africa: a review of 223 cases. Arch Dis Child 1972; 47:20-25.

26. Central Statistical Services of South Africa. Census statistics for South Africa. Central Statistical Services of South Africa 2001. http://www .statssa.gov.za/census01/html/default.asp. Accessed 2 July 2010.

27. Perez-Schael I, Escalona M, Salinas B, Materan M, Perez ME, Gonzalez G. Intussusception-associated hospitalization among Venezuelan infants during 1998 through 2001: anticipating rotavirus vaccines. Pediatr Infect Dis J 2003; 22:234-239.

28. Wu QB, Gu HY, Tang WG, Jin H, Wang B. Distribution signature analysis between intussusception and rotavirus diarrhea in young children. Zhonghua Shi Yan He Lin Chuang Bing Du Xue Za Zhi 2008; 22:216-218.

29. Bines JE, Kohl KS, Forster J, et al. Acute intussusception in infants and children as an adverse event following immunization: case definition and guidelines of data collection, analysis, and presentation. Vaccine $2004 ; 22: 569-574$.

30. Bines JE, Ivanoff B. Acute intussusception in infants and children: a global perspective. Geneva, Switzerland, World Health Organization, 2002.

31. Nelson EA, Tam JS, Glass RI Parashar UD Fok TF. Incidence of rotavirus diarrhea and intussusception in Hong Kong using standardized hospital discharge data. Pediatr Infect Dis J 2002; 21:701-703.

32. Bines JE, Liem NT, Justice FA, et al. Risk factors for intussusception in Vietnam and Australia: adenovirus implicated but not rotavirus. J Pediatr 2006; 149:452-460.

33. Robinson CG, Hernanz-Schulman M, Zhu Y, Griffin MR, Gruber W, Edwards KM. Evaluation of anatomic changes in young children with natural rotavirus infection: is intussusception biologically plausible? J Infect Dis 2004; 189:1382-1387.

34. Beale PG. "Lead point" perforation in intussusception. Paper presented at: South African Association of Paediatric Surgeons Biennial Congress; 5 September 1986; Pretoria, South Africa.

35. Kombo LA, Gerber MA, Pickering LK, Atreya CD, Breiman RF. Intussusception, infection, and immunization: summary of a workshop on rotavirus. Pediatrics 2001; 108:E37.

36. Stringer MD, Pablot SM, Brereton RJ. Paediatric intussusception. $\mathrm{Br}$ J Surg 1992; 79:867-875.

37. Inan M, Aydiner CY, Ayvaz S. Malrotation as a preparing ground for intussusception. Pediatr Surg Int 2003; 19:616.

38. Hays DM, Gwinn JL. The changing face of intussusception. JAMA 1966; $195: 817-820$

39. Davis CF, McCabe AJ, Raine PA. The ins and outs of intussusception: history and management over the past fifty years. J Pediatr Surg 2003; 38:60-64

40. Parashar UD, Glass RI. Rotavirus vaccines: early success, remaining questions. N Engl J Med 2009; 360:1063-1065.

41. Patel MM, Clark AD, Glass RI, et al. Broadening the age restriction for initiating rotavirus vaccination in regions with high rotavirus mortality: benefits of mortality reduction versus risk of fatal intussusception. Vaccine 2009; 27:2916-2922.

42. Goodman M, Lamm SH, Bellman MH. Temporal relationship modelling: DTP or DT immunizations and infantile spasms. Vaccine $1998 ; 16: 225-231$.

43. Andrews N, Miller E, Waight L, et al. Does oral polio vaccine cause intussusception in infants? evidence from a sequence of three selfcontrolled cases series studies in the United Kingdom. Eur J Epidemiol 2001; 17:701-706.

44. Raman T, Mukhopadhyaya A, Eapen CE, et al. Intussusception in southern Indian children: lack of association with diarrheal disease and oral polio vaccine immunization. Indian J Gastroenterol 2003;22: 82-84. 